\title{
Everything Points to Myeloma
}

\author{
Arjun Gupta, MD, Shiraj Sen, MD, PhD, and Ambarish Pandey, MD
}

Department of Internal Medicine, University of Texas Southwestern Medical Center, Dallas, TX, USA.

KEY WORDS: hematology; cancer; clinical images.

J Gen Intern Med 30(6):855

DOI: $10.1007 / \mathrm{s} 11606-015-3215-8$

() Society of General Internal Medicine 2015

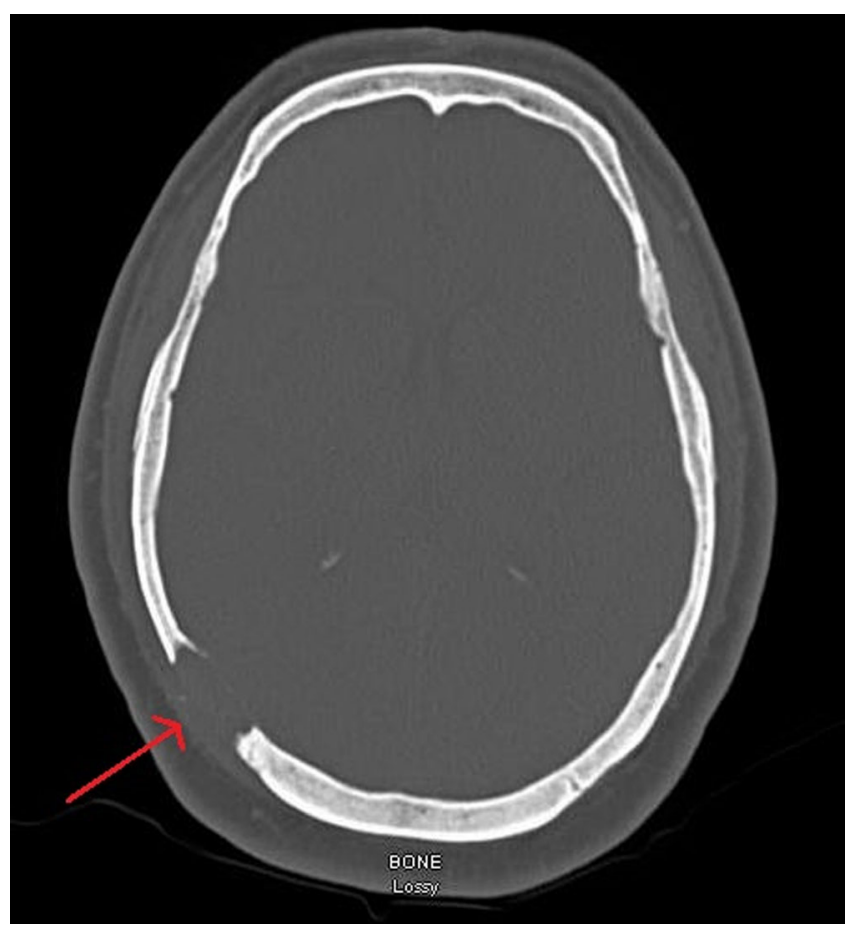

Figure 1. CT of head, demonstrating lytic lesion (arrow) in the right parieto-occipital region.

\section{CASE}

A 45-year-old man with a history of solitary plasmacytoma of the left hip, managed with surgery and radiation therapy 5 years back, was found to have new lytic lesions in his skull, discovered on an annual skeletal survey and confirmed by a head CT (Fig. 1). The patient had no major complaints, an unremarkable physical exam, and a mild anemia (Hemoglobin $=12 \mathrm{mg} / \mathrm{dL}$ ). Due to concern for progression to multiple myeloma, the patient underwent a bone marrow biopsy, which revealed decreased hematopoiesis and $32 \%$ myeloblasts,

$\overline{\text { All authors have had access to all data in the study, read and approved }}$ submission of the letter, and the findings have not been presented previously in any conference or been published in print or electronic format. There are no conflicts of interest to disclose.

Published online February 10, 2015

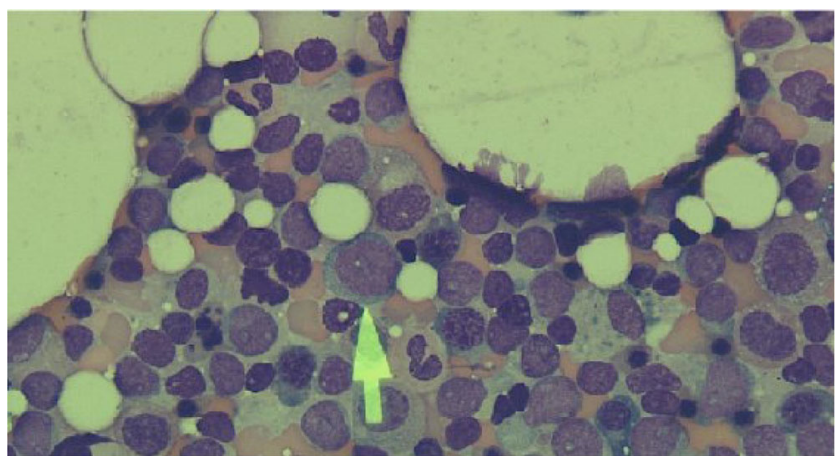

Figure 2. Bone marrow aspirate (100x magnification), arrow pointing to myeloblast.

without evidence of a plasma cell dyscrasia (Fig. 2). Thus, a diagnosis of acute myeloid leukemia (AML) was made and induction chemotherapy was initiated.

Secondary malignancies, including AML, can occur in patients with plasma cell disorders and a history of radiation or chemotherapy, and are associated with a worse prognosis. ${ }^{1}$ More than half of patients with solitary plasmacytoma eventually develop multiple myeloma, despite therapy. ${ }^{2}$ The bone lesions, anemia and history of plasmacytoma in this patient were suspicious for multiple myeloma; however, AML can also present with lytic bone lesions. ${ }^{3}$ Bone marrow examination is essential in the evaluation of both multiple myeloma and AML.

Conflict of Interest: The authors declare that they do not have a conflict of interest.

\section{Funding Sources: None.}

Corresponding Author: Ambarish Pandey, MD; Department of Internal Medicine, University of Texas Southwestern Medical Center, 5323 Harry Hines Blvd, Dallas, TX 75390-9047, USA (e-mail: ambarish.pandey@phhs.org).

\section{REFERENCES}

1. Yang J, Terebelo HR, Zonder JA. Secondary Primary Malignancies in Multiple Myeloma: An Old Nemesis Revisited. Adv. Hematol. 2012;2012:801495.

2. Soutar R, Lucraft H, Jackson G, Reece A, Bird J, Low E, et al. Guidelines on the diagnosis and management of solitary plasmacytoma of bone and solitary extramedullary plasmacytoma. Br. J. Hematol. 2004;124:717-26.

3. Johnson JL, Moscinski L, Zuckerman K. Value of positron emission tomography scan in staging cancers, and an unusual presentation of acute myeloid leukemia. Case 3. Acute myeloid leukemia presenting with lytic bone lesions. J. Clin. Oncol. 2004;22:2968-70. 